\title{
Molecular Docking Evaluation of Some Indonesian's Popular Herbals for a Possible COVID-19 Treatment
}

\author{
Tony Sumaryada ${ }^{1, *} \mathbb{( D}$, Cindy Agnitya Pramudita ${ }^{1}$ \\ 1 Computational Biophysics and Molecular Modeling Research Group (CBMoRG), Department of Physics, IPB University, \\ Jalan Meranti Kampus IPB Dramaga Bogor 16680, Indonesia \\ * Correspondence: tsumaryada@apps.ipb.ac.id;
}

Scopus Author ID 55872955200

Received: 27.08.2020; Revised: 14.09.2020; Accepted: 15.09.2020; Published: 17.09.2020

\begin{abstract}
Indonesia's rich tropical biodiversity offers many possible options for fighting the unprecedented outbreak of coronavirus disease 2019 (COVID-19). In this paper, we evaluate the in silico (molecular docking) performance of some popular herbal supplements and natural remedies, which are usually consumed by Indonesian people and compare them to the docking performance of the control ligand (N3 inhibitor) and some protease-inhibitor drugs. The tested active compounds were grouped based on their popularity in the market, i.e., honey, black seed (Nigella sativa), Javanese turmeric (Curcuma xanthorriza roxb), and mangosteen, which usually served in the form of encapsulated oil or powder. The results show that most of the tested active compounds perform better than N3 inhibitor and protease inhibitor drugs (lopinavir and darunavir) in inhibiting the main protease of SARS-CoV-2 virus of COVID-19 (C19MP). Based on the combined scores of binding affinity, the similarity of active sites (SAS), and the drug-likeness properties of the ligand, gamma mangostin turns out to be the best possible C19MP inhibitor as compared to other ligands. The active site analysis also reveals that His41, Met49, Leu141, and Asn142 are among the most important amino acids that play a significant role in the protein-ligand binding due to their frequent occurrence in the docking simulation.
\end{abstract}

Keywords: COVID-19; Indonesian herbal; molecular docking; main protease-inhibitor.

(C) 2020 by the authors. This article is an open-access article distributed under the terms and conditions of the Creative Commons Attribution (CC BY) license (https://creativecommons.org/licenses/by/4.0/).

\section{Introduction}

The COVID-19 disease, which started at Wuhan, China, has suddenly disrupted all human activities all over the world and becomes a global pandemic problem with a staggering number of infected people and casualties [1,2]. According to worldometer, one of the respected websites that live reporting the development of worldwide cases of this pandemic (https://www.worldometers.info/coronavirus/\#countries), as of September 11, 2020, about 28,361,811 people have been infected with almost 914,464 death in 213 countries. Intensive research has been globally conducted to respond to this unprecedented event and find the cure to halt the progression of this deadly pandemic. Some signs of progress have been achieved by repurposing the malaria drug (chloroquine phosphate) [3-6] and the antiretroviral proteaseinhibitors [7-10] to block the virus replication process. Since minimal information is available up to now, the actual mechanism of COVID-19 infection to the body is still unknown, and more research and ideas are needed in this stage.

The newly deposited structure of COVID-19 main protease protein by [11] has boosted the in-silico research to find the drug for COVID-19 therapy. This protease structure can be accessed in the protein data bank (www.rcsb.org) with the PDB ID 6LU7 (chain A). The main 
protease responsible for the final stage of virus replication inside the cell, so inhibiting this protein will halt the creation of new viruses inside the hijacked cell. Some research groups have already reported their preliminary results on the action of some protease-inhibitor drugs (for example, lopinavir, ritonavir, darunavir, indinavir) on this target [8-10]. In general, those drugs have shown promising potential for COVID-19 treatment, but a further clinical trial must be assessed to confirm their efficacy.

Indonesia has been known as a big country with a mega-biodiversity potential due to its unique location, which lies in the equatorial line and positions between two vast oceans (pacific and Indian ocean). This biodiversity richness has been beneficial to its inhabitant as reflected by various traditional medicines (Jamu) and health treatment based on local wisdom. Some popular herbs and natural remedies, i.e., ginger, Javanese turmeric (temulawak), cinnamon, Andrographis paniculata (sambiloto), propolis, honey, etc. Those herbal sometimes must be prepared and served by following a particular, even tedious procedure. The Indonesian's middle class nowadays prefers a more practical way of consuming the herbal via a tablet or capsule form, and this fact has boosted the Indonesian herbal supplement industry. Some of the popular herbal supplements and natural remedies in the Indonesian market right now are Javanese turmeric, honey, garlic oil, and black seed oil (habbatussauda). Even though the black seed is not a native Indonesian plant, but due to a religious matter, this herbal had become one of the most popular herbal supplement in the Indonesian market.

Molecular docking is a fast and practical computational approach to evaluate the potential of ligands in inhibiting the protein/enzyme. The interactions between protein and ligand are calculated based on the biophysical concept (electrostatic and thermodynamic approach) to produce the score function (in terms of binding affinity) and the best binding pose that reflects the likeliness of a particular ligand to be developed into a new drug. It is not strange that in the wake of a global pandemic event, molecular docking becomes the favorite and first approach taken by scientists to find the cure of COVID-19. In this paper, we evaluate the molecular docking performance of the active compounds of some popular Indonesian herbal supplements. The tested ligands in this research are grouped into five different assumed sources, i.e., (i) black seed (dithymoquinone, artesin, nigellidine) [12], (ii) Javanese turmeric (curcumin, demethoxy curcumin, bisdemethoxycurcumin) [13], (iii) mangosteen (alpha mangostin, beta mangostin, gamma mangostin, xanthone), (iv) honey (galangin, luteolin, quercetin, kaempferol) [14] and (v) protease-inhibitor drugs (lopinavir, darunavir) [9]. The docking performance of those ligands was then compared to the N3 inhibitor (the control ligand), which was found in the COVID-19 main protease crystal structure. Note that this study is limited by the use of the molecular docking method only to give us a glimpse of the efficacy and potential of some popular herbals and natural remedies in combating the COVID-19 pandemic. Further advancement of this study by using a molecular dynamics simulation (to capture more snapshots and binding poses) is our ongoing project.

\section{Materials and Methods}

\subsection{Preparation of ligands and COVID-19 main protease target.}

The target for the docking simulation is chain A of COVID-19 main protease (C19MP). The structure of C19MP was deposited by Ref [11] and can be downloaded from www.rcsb.org with the PDB ID 6LU7 (see Figure 1). This protease structure must be cleaned first from water molecules and its inhibitor (N3 peptide) using Chimera software [15], then saved in *.pdb 
format. This file was then prepared for docking by adding the polar hydrogen atoms and Gasteiger charges using Autodock Tools ADT 1.5.6 and minimized and saved in the *.pdbqt extension [16]. The 3D structure of ligands in the *.sdf format were downloaded from https://pubchem.ncbi.nlm.nih.gov. There are 16 tested ligands, which consist of 14 active compounds of herbal (natural remedy) and two protease-inhibitor drugs. The control ligand in this research is the N3 inhibitor. The 3D structure of ligands in *.sdf format then converted into *.pdb format using Chimera software. The polar hydrogen bonds and the Gasteiger charges also added to the ligand before it was minimized and saved in *.pdbqt format using Autodock Tools ADT 1.5.6.

\subsection{Molecular docking setup.}

The targeted docking simulations were performed by using a grid box which size was determined from the interaction pocket of $\mathrm{N} 3$ on C19MP protein. The grid box size was set to $\mathrm{x}=46 \AA, \mathrm{y}=46 \AA, \mathrm{z}=52 \AA$, and the center point was set to $\mathrm{x}=-13.691, \mathrm{y}=13.718$, and $\mathrm{z}=62.719$. The number of exhaustiveness and the number of modes was set to 20 to obtain a more accurate result. All simulations were performed by using the Autodock Vina program [17] and run in a desktop computer with Intel Core i7-4790, $3.60 \mathrm{GHz}$ processor, and $8 \mathrm{~GB}$ of RAM, under Windows 8.1 and 64-bit platform.

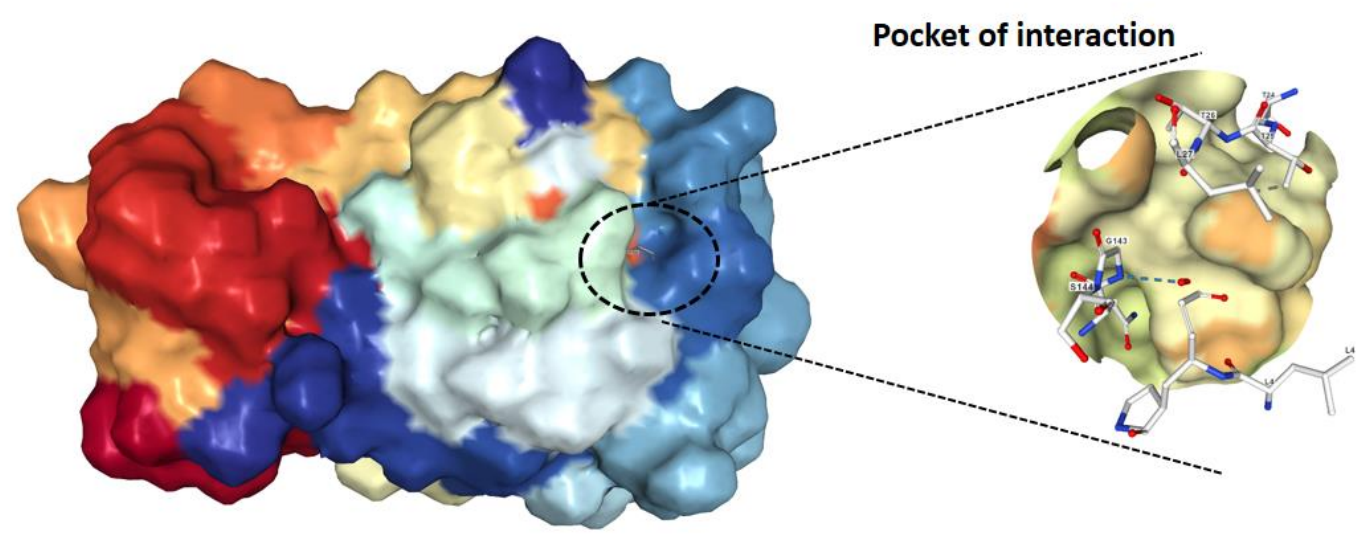

Figure 1. Surface representation of COVID-19 main protease and its zoomed pocket of interaction with N3 inhibitor. Figure retrieved from protein data bank website at http://www.rcsb.org/3d-view/6LU7/1.

\section{Results and Discussion}

\subsection{Binding affinity analysis.}

The redocking of the N3 inhibitor produced the binding affinity of $\Delta \mathrm{G}=-6.0 \mathrm{kcal} / \mathrm{mol}$; this value, along with the region of the binding site, was used as a standard (comparator) for determining the docking performance of other ligands. The binding affinity performance of each ligand is shown in Figure 2. The binding affinity of the evaluated compounds of black seed (artesin dithymoquinone, nigellidine) is better as compared to N3, with nigellidine score the highest $\Delta \mathrm{G}=-7.8 \mathrm{kcal} / \mathrm{mol}$. The binding affinity of nigellidine is also better than the protease drug inhibitors, darunavir and lopinavir $(\Delta \mathrm{G}=-7.0$ and $-7.40 \mathrm{kcal} / \mathrm{mol}$ respectively). The binding affinity of lopinavir is the best among other protease drugs and in agreement with the 
molecular docking study performed by Ref [18]. The binding affinity of the active compounds of Javanese turmeric is better than N3 but still below the protease drug inhibitor (lopinavir). Bisdemethoxycurcumin scores the best binding affinity in this herbal group $(\Delta G=-7.0$ $\mathrm{kcal} / \mathrm{mol}$ ) and similar to one of the protease drug inhibitors, darunavir.

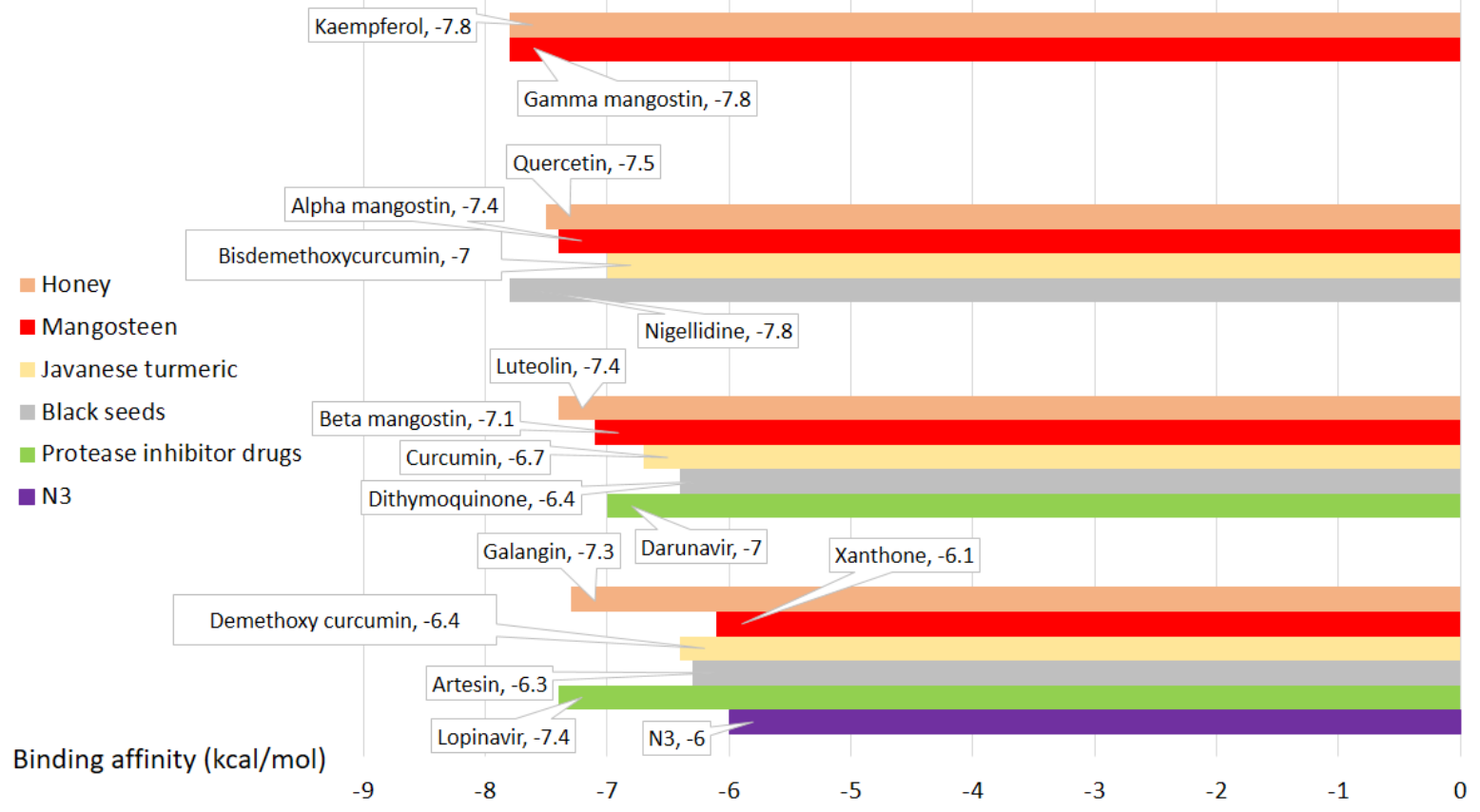

Figure 2. Binding affinity of some active compounds of herbal (natural) remedies as compared to proteaseinhibitor drugs and N3 inhibitor.

Honey contains many flavonoids and phenolics compounds, which has been widely known to have potential as anti-bacterial, anti-inflammation, and antiviral activity [14]. The flavonoid content such as apigenin, kaempferol, galangin, quercetin, and luteolin are not just found in honey but also other sources like ginger, bitter melon, aloe vera [19], chamomile [20], and galangal [21]. From four active compounds of honey evaluated, all of them perform better than $\mathrm{N} 3$ inhibitor, with kaempferol scoring the highest binding affinity of $\Delta \mathrm{G}=-7.8 \mathrm{kcal} / \mathrm{mol}$. In addition to kaempferol, quercetin $(\Delta \mathrm{G}=-7.5 \mathrm{kcal} / \mathrm{mol})$ also performs better than the protease-inhibitor drug (lopinavir and darunavir). Similar results that support the potential of kaempferol and quercetin in inhibiting the main protease of SARS-CoV-2 were discussed by Ref [22].

\subsection{Molecular interaction and binding pose analysis.}

The docking performance of a ligand can also be evaluated from the similarity of the active sites (SAS), which shows the percentage of overlapping between ligand and control ligand in occupying the binding pocket. The SAS of the five best ligands is shown in Table 1. The number of residues involved in the binding interaction with the N3 inhibitor is 24 residues. As we compare the similarity of the active sites (SAS) of the leading ligands with the N3 inhibitor, some interesting facts emerged here. The strong binding affinity is not always followed by a high percentage of SAS, as seen in Table 1 . Three ligands with the best binding affinity $(\Delta \mathrm{G}=-7.8 \mathrm{kcal} / \mathrm{mol})$, Kaempferol, Gamma mangostin, and Nigellidine have the SAS percentage of $71 \%, 63 \%$, and $54 \%$, respectively. The bisdemethoxycurcumin, even though only having $\Delta \mathrm{G}=-7.0 \mathrm{kcal} / \mathrm{mol}$, turns out to have the best $\mathrm{SAS}$ with a score of $79 \%$ similarity. This compound is geometrically more fit to enter the binding pocket of $\mathrm{N} 3$ as compared to 
other herbal compounds. This similarity can be seen visually in the ligand's binding pose in Figure 3, where bisdemethoxycurcumin resides in an almost similar pocket to an N3 inhibitor. Three ligands with the best binding affinity $(\Delta \mathrm{G}=-7.8 \mathrm{kcal} / \mathrm{mol})$, Gamma mangostin, Kaempferol, and Nigellidine have the SAS percentage below bisdemethoxycurcumin but still better than lopinavir. Those three ligands reside in the pocket, which is slightly off from the N3's interaction pocket. The detailed list of residues involved in the molecular interactions of each ligand as compared to N3's residues is shown in Figure 4. Bisdemethoxycurcumin has a similar list of residues as an N3 inhibitor except for Cys44, Thr45, Ser46, and His172. It was also found that none of the tested ligands here has interaction with His172. The detailed molecular interaction of each ligand in their pocket as compared to N3's pocket is shown in Figure 5.

Table 1. Binding performance of a leading ligand with a binding affinity better than N3 inhibitor.

\begin{tabular}{l|l|l|l} 
Ligand & Source & $\begin{array}{l}\text { Binding affinity } \\
(\mathbf{k c a l} / \mathbf{m o l})\end{array}$ & $\begin{array}{l}\text { SAS, Similarity } \\
\text { of active sites } \\
(\boldsymbol{\%})\end{array}$ \\
\hline Gamma mangostin & Mangosteen & -7.8 & 63 \\
\hline Kaempferol & Honey & -7.8 & 71 \\
\hline Nigellidine & Black seed & -7.8 & 54 \\
\hline Lopinavir & Protease-inhibitor drug & -7.4 & 50 \\
\hline Bisdemethoxycurcumin & Javanese turmeric & -7.0 & 79
\end{tabular}

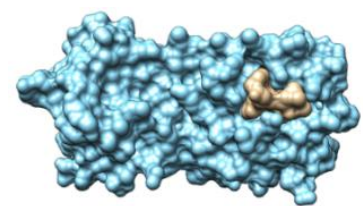

$\mathrm{N} 3, \Delta \mathrm{G}=-6.0 \mathrm{kcal} / \mathrm{mol}$

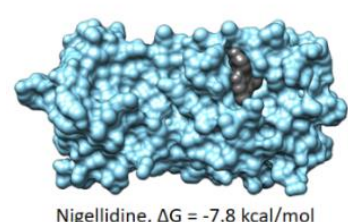

Nigellidine, $\Delta \mathrm{G}=-7.8 \mathrm{kcal} / \mathrm{mol}$

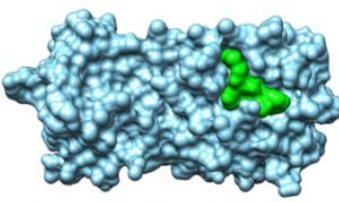

Lopinavir, $\Delta \mathrm{G}=-7.4 \mathrm{kcal} / \mathrm{mol}$

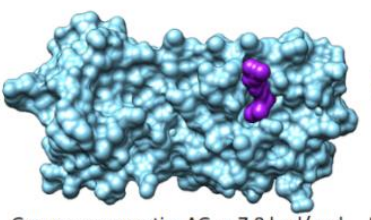

Gamma-mangostin, $\Delta \mathrm{G}=-7.8 \mathrm{kcal} / \mathrm{mol}$ Bisdemethoxycurcumin $\Delta \mathrm{G}=-7.0 \mathrm{kcal} / \mathrm{mol}$
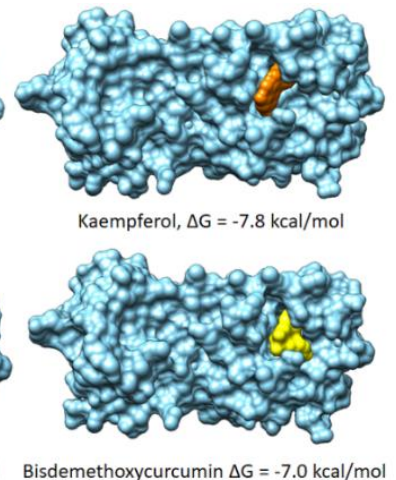

Figure 3. Binding pose of the leading active compound of each herbal group as compared to N3 and lopinavir in the surface representations.

\begin{tabular}{|c|l|l|l|l|l|l|}
\hline $\begin{array}{c}\text { Ligand } \\
\text { Residue }\end{array}$ & N3 & Lopinavir & Nigellidine & Kaempferol & Bisdemethoxycurcumin & Gamma mangostin \\
\hline Thr24 & & & & & & \\
\hline Thr25 & & & & & & \\
\hline Thr26 & & & & & & \\
\hline Leu27 & & & & & & \\
\hline His41 & & & & & & \\
\hline Cys44 & & & & & & \\
\hline Thr45 & & & & & & \\
\hline Ser46 & & & & & & \\
\hline Met49 & & & & & & \\
\hline Tyr54 & & & & & & \\
\hline Phe140 & & & & & & \\
\hline Leu141 & & & & & & \\
\hline Asn142 & & & & & & \\
\hline Gly143 & & & & & & \\
\hline Ser144 & & & & & & \\
\hline Cys145 & & & & & & \\
\hline His163 & & & & & & \\
\hline His164 & & & & & & \\
\hline Met165 & & & & & & \\
\hline Glu166 & & & & & & \\
\hline His12 & & & & & & \\
\hline Asp187 & & & & & & \\
\hline Arg188 & & & & & & \\
\hline Gln189 & & & & & & \\
\hline
\end{tabular}

Figure 4. Residues involved in the molecular interaction with the leading active compounds of each herbal group as compared to N3 inhibitor. Note: the blue color denotes the residue involved in the interaction with a particular ligand. 


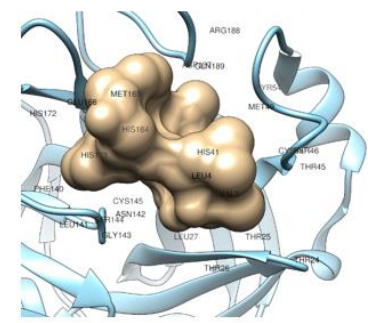

N3

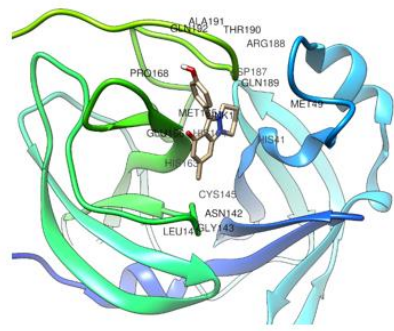

Nigellidine

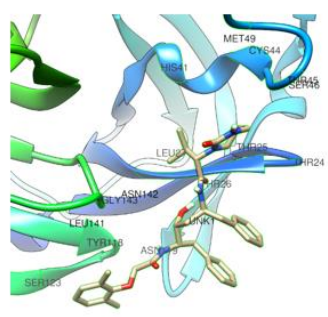

Lopinavir

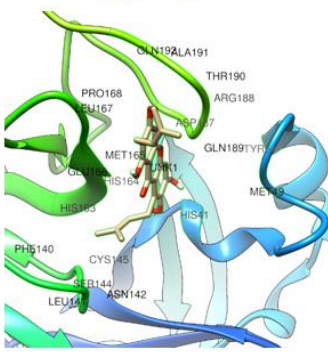

Gamma-mangostin

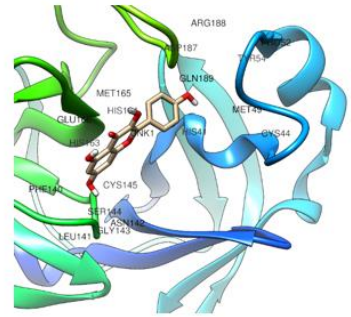

Kaempferol

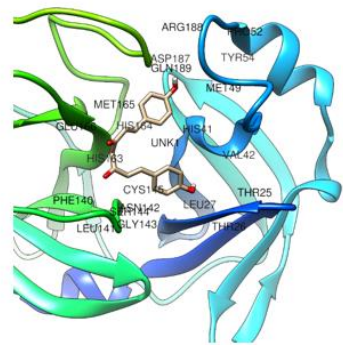

Bisdemethoxycurcumin

Figure 5. Detailed molecular interactions of the leading active compound of each herbal group as compared to N3 inhibitor and protease-inhibitor drugs (lopinavir).

From five leading ligands evaluated here, the residues that play an important role (always present) during the ligand-protease binding have been identified and shown in Figure 6. Some residues, His41, Met49, Leu141, and Asn142 always present in all ligand-protease binding. The next important residues involved in the ligands-C19MP interactions are Gly143, Cys145, His163, His164, Met165, Glu166, Asp187, Arg188, Gln189. The importance of His 41, Cys145, and Leu141 residues for ligand-protease binding, as found in this research, is also discussed in Ref [10, 23].

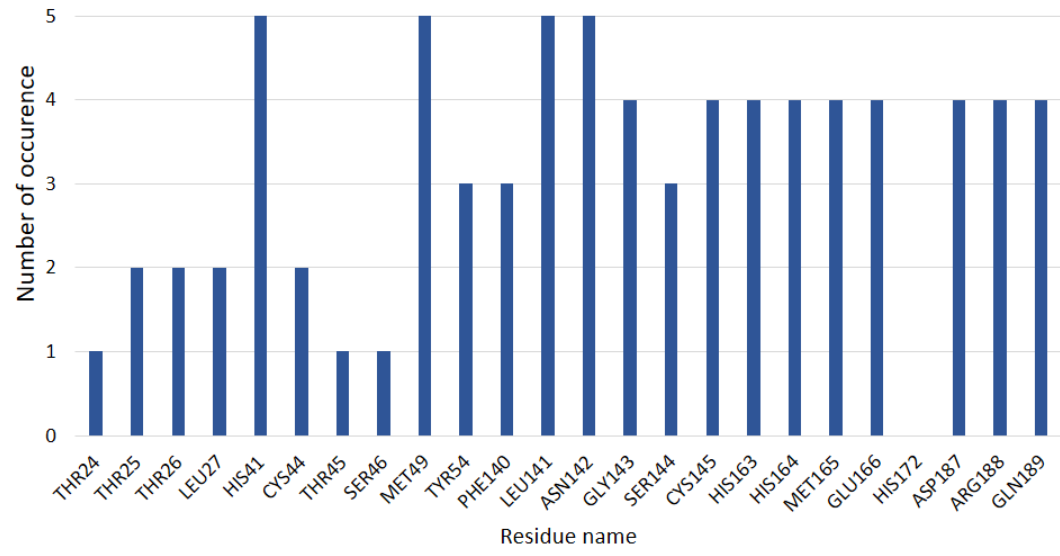

Figure 6. Frequency of occurrence of the residues involved in the binding interaction of the leading active compound of each herbal group as compared to the $\mathrm{N} 3$ active sites.

\subsection{The physicochemical and pharmacochemical analysis of the tested ligands.}

Using the online molecular modeling tools SwissADME [24], we can compute the physicochemical descriptor and the ADME (absorption, distribution, metabolism, and elimination) parameters of each tested ligand. The drug-likeness of a particular ligand is shown in a radar-like representation, as shown in Figure 7. The ideal drug candidate must have physicochemical and pharmacochemical values (as depicted by solid red lines) inside the pink- 
colored hexagonal boundary. Nigellidine has all the drug-likeness parameters, stay inside the pink-colored hexagonal shape, and based on those molecular properties. It is the potential to be developed as a drug candidate. However, there is one drawback of nigellidine, the number of the rotatable bond, which only one causes the ligand to become very stiff and makes it difficult for the ligand to fit into the interaction pocket as shown by Figure 3, and its low percentage of SAS of 54\%. Bisdemethoxycurcumin has most of the 'parameter's values inside the hexagonal boundary, except for the insaturation property, which is above the ideal limit. The insaturation property shows the fraction of carbon in the $\mathrm{sp}^{3}$ hybridization to the regular carbon. The higher number of rotatable bonds makes this ligand flexible and better fit into the interaction pocket. Kaempferol has most of its drug-likeness properties below the maximum limit, except for the insaturation property that exceeds the ideal limit. The physicochemical and pharmacochemical values of gamma mangostin, as shown by the area under the solid red lines, almost perfectly superimpose the hexagonal boundary of the ideal drug properties. Even though the flexibility of gamma mangostin is not optimum (four rotatable bonds), but overall, the druglikeness of gamma mangostin is the best among other ligands. The efficacy of gamma mangostin in combating the viral-based disease is also suggested by some References [25, 26]. Lopinavir is a standard protease drug in this research that shows the best physicochemical and pharmacochemical properties, as shown by its overlapping area on the hexagonal-shape. The bigger number of the molecular weight $(628.80 \mathrm{~g} / \mathrm{mol})$ and rotatable bonds (17 rotatable bonds) makes lopinavir too big and too flexible in inhibiting the interaction pocket of C19MP and has a less score in binding affinity as compared to other ligands (nigellidine, gamma mangostin, kaempferol, and quercetin).

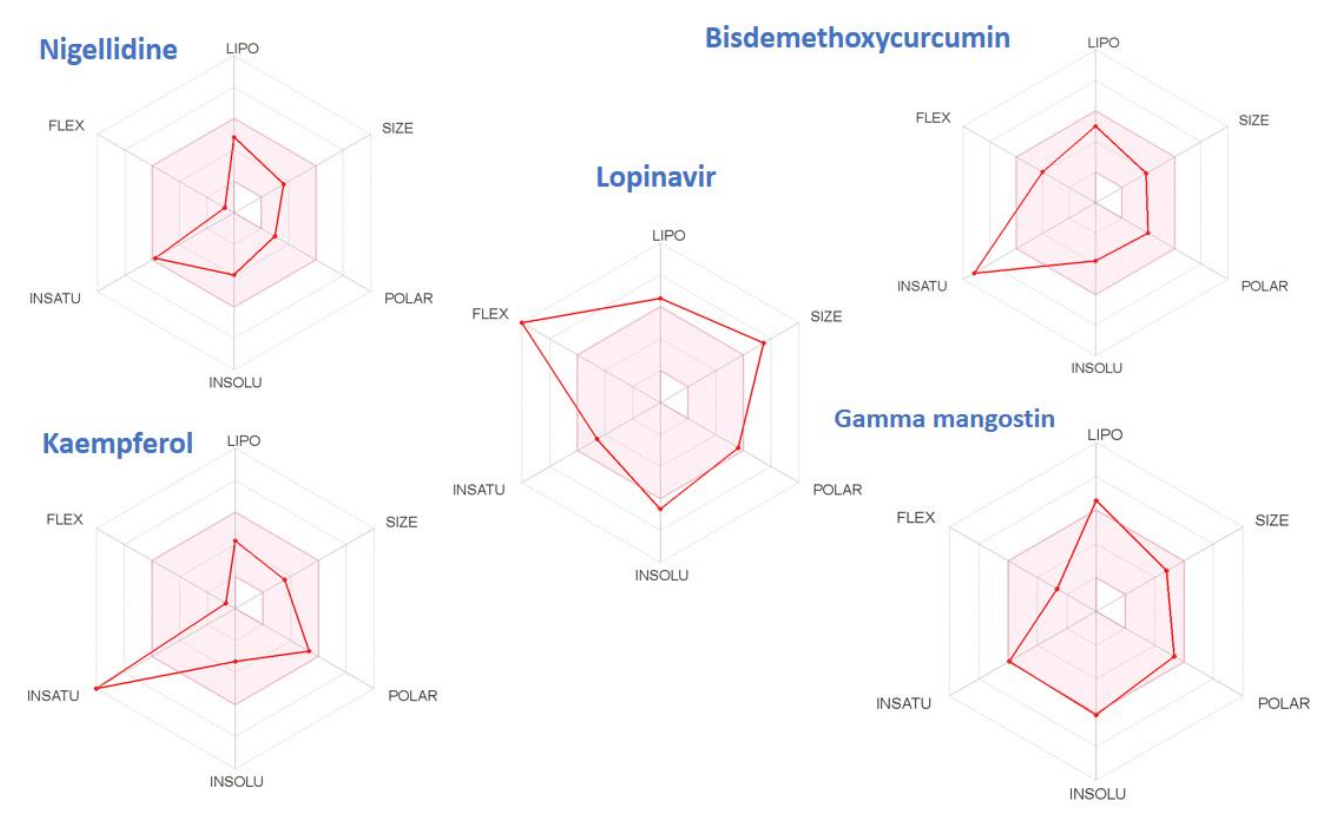

Figure 7. Radar-like representation of the drug-likeness of the leading active compounds of each herbal group calculated by SwissADME, the online server database.

\section{Conclusions}

The molecular docking evaluation of some popular Indonesian herbal and natural remedies on COVID-19 main protease target has been performed. All of the tested ligands scores a binding affinity better than the N3 inhibitor (lower than $-6.0 \mathrm{kcal} / \mathrm{mol}$ ). Three active compounds from honey, one from mangosteen, and one from black seed score binding affinity, 
which is better than lopinavir, the protease drug (lower than $-7.4 \mathrm{kcal} / \mathrm{mol}$ ). Further docking pose analysis by looking at the similarity of active sites (SAS) uncovers the useful pieces of information regarding the fitness of ligands in inhibiting the binding pocket of C19MP as compared to N3 inhibitor. Based on SAS, bisdemethoxycurcumin has shown the best pocket fitting of $79 \%$. However, based on the combined scores of binding affinity, SAS, and the druglikeness property of the ligand, gamma mangostin turns out to be the best possible inhibitor of the chain A of the main protease of SARS-CoV-2 (C19MP) as compared to other ligands. The active site analysis also reveals that His41, Met49, Leu141, and Asn142 among the most important amino acids due to their frequent occurrence in the ligand-protein binding.

\section{Funding}

This research received no external funding.

\section{Acknowledgments}

The authors express their gratitude for the computational support from the Department of Physics, IPB University.

\section{Conflicts of Interest}

The authors declare no conflict of interest.

\section{References}

1. Wu, F.; Zhao, S.; Yu, B.; Chen, Y.-M.; Wang, W.; Song, Z.-G.; Hu, Y.; Tao, Z.-W.; Tian, J.-H.; Pei, Y.-Y.; Yuan, M.-L.; Zhang, Y.-L.; Dai, F.-H.; Liu, Y.; Wang, Q.-M.; Zheng, J.-J.; Xu, L.; Holmes, E.C.; Zhang, Y.-Z. A new coronavirus associated with human respiratory disease in China. Nature 2020, 579, 265-269, https://doi.org/10.1038/s41586-020-2008-3.

2. Zhou, P.; Yang, X.-L.; Wang, X.-G.; Hu, B.; Zhang, L.; Zhang, W.; Si, H.-R.; Zhu, Y.; Li, B.; Huang, C.L.; Chen, H.-D.; Chen, J.; Luo, Y.; Guo, H.; Jiang, R.-D.; Liu, M.-Q.; Chen, Y.; Shen, X.-R.; Wang, X.; Zheng, X.-S.; Zhao, K.; Chen, Q.-J.; Deng, F.; Liu, L.-L.; Yan, B.; Zhan, F.-X.; Wang, Y.-Y.; Xiao, G.-F.; Shi, Z.-L. A pneumonia outbreak associated with a new coronavirus of probable bat origin. Nature 2020, 579, 270-273, https://doi.org/10.1038/s41586-020-2012-7.

3. Gao, J.; Tian, Z.; Yang, X. Breakthrough: Chloroquine phosphate has shown apparent efficacy in treatment of COVID-19 associated pneumonia in clinical studies. BioScience Trends 2020, 14, 72-73, https://doi.org/10.5582/bst.2020.01047.

4. Devaux, C.A.; Rolain, J.-M.; Colson, P.; Raoult, D. New insights on the antiviral effects of chloroquine against coronavirus: what to expect for COVID-19? International Journal of Antimicrobial Agents 2020, 55, https://doi.org/10.1016/j.ijantimicag.2020.105938.

5. Pastick, K.A.; Okafor, E.C.; Wang, F.; Lofgren, S.M.; Skipper, C.P.; Nicol, M.R.; Pullen, M.F.; Rajasingham, R.; McDonald, E.G.; Lee, T.C.; Schwartz, I.S.; Kelly, L.E.; Lother, S.A.; Mitjà, O.; Letang, E.; Abassi, M.; Boulware, D.R. Review: Hydroxychloroquine and Chloroquine for Treatment of SARSCoV-2 (COVID-19). Open Forum Infectious Diseases 2020, 7, https://doi.org/10.1093/ofid/ofaa130.

6. Gautret, P.; Lagier, J.-C.; Parola, P.; Hoang, V.T.; Meddeb, L.; Mailhe, M.; Doudier, B.; Courjon, J.; Giordanengo, V.; Vieira, V.E.; Tissot Dupont, H.; Honoré, S.; Colson, P.; Chabrière, E.; La Scola, B.; Rolain, J.-M.; Brouqui, P.; Raoult, D. Hydroxychloroquine and azithromycin as a treatment of COVID-19: results of an open-label non-randomized clinical trial. International Journal of Antimicrobial Agents 2020, 56, https://doi.org/10.1016/j.ijantimicag.2020.105949.

7. Wu, C.; Liu, Y.; Yang, Y.; Zhang, P.; Zhong, W.; Wang, Y.; Wang, Q.; Xu, Y.; Li, M.; Li, X.; Zheng, M.; Chen, L.; Li, H. Analysis of therapeutic targets for SARS-CoV-2 and discovery of potential drugs by computational methods. Acta Pharmaceutica Sinica B 2020, 10, 766-788, https://doi.org/10.1016/j.apsb.2020.02.008.

8. Lin, S.; Shen, R.; He, J.; Li, X.; Guo, X. Molecular Modeling Evaluation of the Binding Effect of Ritonavir, Lopinavir and Darunavir to Severe Acute Respiratory Syndrome Coronavirus 2 Proteases. bioRxiv 2020, https://doi.org/10.1101/2020.01.31.929695. 
9. $\quad$ Chang, Y.; Tung, Y.; Lee, K.; Chen, T.; Hsiao, Y.; Chang, H.; Hsieh, T.; Su, C.; Wang, S.; Yu, J.; Shih, S.; Lin, Y.; Lin, Y.; Tu, Y.E.; Tung, C.; Chen, C. Potential Therapeutic Agents for COVID-19 Based on the Analysis of Protease and RNA Polymerase Docking. Virol. J. 2020, https://doi.org/10.20944/preprints202002.0242.v1.

10. Ton, A.-T.; Gentile, F.; Hsing, M.; Ban, F.; Cherkasov, A. Rapid Identification of Potential Inhibitors of SARS-CoV-2 Main Protease by Deep Docking of 1.3 Billion Compounds. Molecular Informatics 2020, 39 , https://doi.org/10.1002/minf.202000028.

11. Jin, Z.; Du, X.; Xu, Y.; Deng, Y.; Liu, M.; Zhao, Y.; Zhang, B.; Li, X.; Zhang, L.; Peng, C.; Duan, Y.; Yu, J.; Wang, L.; Yang, K.; Liu, F.; Jiang, R.; Yang, X.; You, T.; Liu, X.; Yang, X.; Bai, F.; Liu, H.; Liu, X.; Guddat, L.W.; Xu, W.; Xiao, G.; Qin, C.; Shi, Z.; Jiang, H.; Rao, Z.; Yang, H. Structure of Mpro from SARS-CoV-2 and discovery of its inhibitors. Nature 2020, 582, 289-293, https://doi.org/10.1038/s41586020-2223-y.

12. Randhawa, M.A.; Alghamdi, M.S. Anticancer Activity of Nigella sativa (Black Seed) - A Review. The American Journal of Chinese Medicine 2011, 39, 1075-1091, https://doi.org/10.1142/S0192415X1100941X.

13. Lew, K. F.; Goh, G. L.; Son, R.; Rukayadi, Y. Effect of Javanese Turmeric (Curcuma Xanthorrhiza Roxb.) Extract on Natural Microflora of Oyster Mushroom (Pleurotus Sajur-Caju) and Its Sensory Acceptability. Int. Food Res. J. 2015, 22, 2446-2451.

14. Cianciosi, D.; Forbes-Hernández, T.Y.; Afrin, S.; Gasparrini, M.; Reboredo-Rodriguez, P.; Manna, P.P.; Zhang, J.; Bravo Lamas, L.; Martínez Flórez, S.; Agudo Toyos, P.; Quiles, J.L.; Giampieri, F.; Battino, M. Phenolic Compounds in Honey and Their Associated Health Benefits: A Review. Molecules 2018, 23, https://doi.org/10.3390/molecules23092322.

15. Pettersen, E.F.; Goddard, T.D.; Huang, C.C.; Couch, G.S.; Greenblatt, D.M.; Meng, E.C.; Ferrin, T.E. UCSF Chimera - A Visualization System for Exploratory Research and Analysis. J. Comput. Chem. 2004, 25 , 1605-1612.

16. Morris, G.M.; Ruth, H.; Lindstrom, W.; Sanner, M.F.; Belew, R.K.; Goodsell, D.S.; Olson, A.J. Software News and Updates AutoDock4 and AutoDockTools4: Automated Docking with Selective Receptor Flexibility. J. Comput. Chem. 2009, 30, 2785-2791.

17. Oleg, T.; Arthur J., O. AutoDock Vina: Improving the Speed and Accuracy of Docking with a New Scoring Function, Efficient Optimization, and Multithreading. J. Comput. Chem., 2010. https://doi.org/10.1002/jcc.21334.

18. Peele, K.A.; Potla Durthi, C.; Srihansa, T.; Krupanidhi, S.; Ayyagari, V.S.; Babu, D.J.; Indira, M.; Reddy, A.R.; Venkateswarulu, T.C. Molecular docking and dynamic simulations for antiviral compounds against SARS-CoV-2: A computational study. Informatics in Medicine Unlocked 2020, 19, https://doi.org/10.1016/j.imu.2020.100345.

19. Kumar, S.; Pandey, A.K. Chemistry and Biological Activities of Flavonoids: An Overview. The Scientific World Journal 2013, 2013, https://doi.org/10.1155/2013/162750.

20. Şanlı, S.; Lunte, C. Determination of eleven flavonoids in chamomile and linden extracts by capillary electrophoresis. Analytical Methods 2014, 6, 3858-3864, https://doi.org/10.1039/c3ay41878b.

21. Basri, A.M.; Taha, H.; Ahmad, N. A Review on the Pharmacological Activities and Phytochemicals of Alpinia Officinarum (Galangal) Extracts Derived from Bioassay-Guided Fractionation and Isolation. Pharmacognosy Reviews 2017, 11, https://doi.org/10.4103/phrev.phrev_55_16.

22. Zhang, D.-H.; Wu, K.-L.; Zhang, X.; Deng, S.-Q.; Peng, B. In silico screening of Chinese herbal medicines with the potential to directly inhibit 2019 novel coronavirus. Journal of Integrative Medicine 2020, 18, 152158, https://doi.org/10.1016/j.joim.2020.02.005.

23. Bharadwaj, S.; Lee, K.E.; Dwivedi, V.D.; Kang, S.G. Computational insights into tetracyclines as inhibitors against SARS-CoV-2 Mpro via combinatorial molecular simulation calculations. Life Sciences 2020, 257 , https://doi.org/10.1016/j.lfs.2020.118080.

24. Daina, A.; Michielin, O.; Zoete, V. SwissADME: a free web tool to evaluate pharmacokinetics, drug-likeness and medicinal chemistry friendliness of small molecules. Scientific Reports 2017, 7, https://doi.org/10.1038/srep42717.

25. Ni, L.; Chen, L.; Huang, X.; Han, C.; Xu, J.; Zhang, H.; Luan, X.; Zhao, Y.; Xu, J.; Yuan, W.; et al. Combating COVID-19 with Integrated Traditional Chinese and Western Medicine in China. Acta Pharmaceutica Sinica B 2020, 1149-1162, https://doi.org/10.1016/j.apsb.2020.06.009.

26. Fatima, I.; Kanwal, S.; Mahmood, T. Natural Products Mediated Targeting of Virally Infected Cancer. DoseResponse 2019, https://doi.org/10.1177/1559325818813227. 